\title{
Mudanças ideacionais das representações linguísticas do heterônimo Álvaro de Campos na obra literária de Fernando Pessoa e em sua tradução para a Língua Inglesa \\ Ideational shifts of the linguistic representations of Álvaro de Campos in Fernando Pessoa's oeuvre and their translations into the English language
}

\author{
Adail Sebastião RodRIGUES-JÚNIOR (Universidade Federal de Ouro Preto) \\ Simone GarCiA de OliveIRA (Instituto Federal de Minas Gerais)
}

\section{RESUMO}

Este estudo propõe uma análise comparativa das representações poéticas do heterônimo pessoano Álvaro de Campos. O corpus investigado são os poemas traduzidos por Richard Zenith para a língua inglesa e seus respectivos originais. Esta pesquisa discute se as construções textuais do heterônimo nos poemas traduzidos apresentam equivalência com os originais, tendo como base para as análises o conceito de mudança proposto por Catford (1965), mas avançando na discussão dos elementos de transitividade, da Gramática Sistêmico Funcional proposta por Halliday \& Matthiessen (2004). Os procedimentos metodológicos foram, primeiramente, a identificação, classificação e interpretação dos elementos oracionais, de modo a verificar se as possiveis mudanças nos tipos de processos e circunstâncias reelaboraram, de alguma maneira, os significados ideacionais do heterônimo na tradução. A pesquisa mostrou que, apesar das mudanças ideacionais ocorridas em alguns versos, o “eu” lírico, representado por Álvaro de Campos, apresentou na tradução uma construção textual bastante similar à do original. De igual modo, as representações do mundo ficcional do heterônimo não sofreram mudanças, o que revela grande preocupação por parte do tradutor em manter a equivalência semântica em suas escolhas lexicais.

Palavras-chave: Gramática Sistêmico-Funcional; Transitividade; Mudança Ideacional; Álvaro de Campos.

D.E.L.T.A., 31-2, 2015 (391-410) 


\section{ABSTRACT}

This study proposes a comparative analysis of the poetic representations of Fernando Pessoa's heteronym Álvaro de Campos. The corpora investigated are the poems translated by Richard Zenith into the English language and their originals. Stemming from the concept of shift proposed by Catford (1965), this study expands the concept by adding to it some transitivity elements from Halliday \& Matthiessen's Systemic Functional Grammar (2004). Bearing this in mind, the paper discusses whether the textual constructions of the analyzed poems show equivalence with their original. The methodological procedures for that were primarily the identification, classification and interpretation of the clause elements in order to verify whether the possible shifts in the types of processes and circumstances change, somehow, the heteronym's ideational meanings in the translation. The research has shown that the lyrical "I", represented by Álvaro de Campos in the translation, presents a somewhat similar textual construction when compared to the original. Likewise, the heteronym's fictional world representations have not changed in the translated text, which reveals a great concern from the translator's part in keeping a semantic equivalence in the lexical choices he made.

Key-words: Systemic Functional Grammar; Transitivity; Ideational-Shift; Álvaro de Campos.

\section{O escopo da pesquisa}

Neste estudo, propomos realizar uma análise comparativa das representações poéticas do heterônimo pessoano Álvaro de Campos à luz dos pressupostos teóricos da Gramática Sistêmico-Funcional (Halliday \& Matthiessen 2004) e a partir do conceito de mudança discriminado no trabalho de Catford (1965) e rediscutido em Matthiessen (2001). Mais especificamente, o objetivo principal deste trabalho é investigar, a partir da metafunção ideacional da linguagem, informada pela teoria sistêmico-funcional hallidayana, como o heterônimo Álvaro de Campos foi representado linguisticamente na tradução de Richard Zenith, por meio da análise comparativa entre os poemas traduzidos e seus respectivos originais. Nosso interesse nessa investigação recai sobre a importância do oeuvre do escritor português para a obra literária lusitana. Sem o nome do autor "Fernando Pessoa", considerado hoje, segundo 
inúmeros estudiosos de sua prolífica produção literária, o maior poeta da língua portuguesa, não se poderia compreender o intricado jogo de desfiguração e refiguração autoral e textual que o escritor português cria no diálogo entre os vários outros nomes de autor através dos quais escolhe se apresentar (Buescu 2010). Em uma de suas cartas (cf.: Martins 2010), diz que o ponto central de sua personalidade como artista é ser um poeta dramático, tendo em tudo quanto escreve a exaltação íntima do poeta e a despersonalização do dramaturgo.

No Dicionário de Fernando Pessoa e do Modernismo Português, Martins (2010) nos revela que Pessoa mesmo define o que seus três principais heterônimos deveriam sentir:

Caeiro tem uma disciplina: as coisas devem ser sentidas tal como são. Ricardo Reis tem outro tipo de disciplina: as coisas devem ser sentidas, não só como são, mas também de modo a enquadrar-se num certo ideal de medida e regra clássicas. Em Álvaro de Campos, as coisas devem simplesmente ser sentidas. (p.326)

É este heterônimo, Álvaro de Campos - o qual tinha o dever, segundo seu criador, de sentir todas as coisas -, o foco deste artigo. Segundo Lopes (2007), ele foi subversor, moderno, avesso à disciplina, intenso e arrogante; sua escrita denotava uma inquietação, tanto interior como exterior. Como, então, foi traduzida a poética pessoana de Álvaro de Campos para a língua inglesa? Ao lançar mão da abordagem textual hallidayana aplicada à tradução, entendemos que, por meio da identificação, classificação e interpretação dos elementos oracionais, é-nos possível verificar se as possíveis mudanças nos tipos de processos e circunstâncias transformaram de algum modo os significados ideacionais da tradução. A partir dessa ponderação, a análise proposta tenciona responder às seguintes perguntas: Como Álvaro de Campos é construído textualmente nos poemas analisados? A construção linguística do heterônimo nos poemas possui níveis de equivalência ${ }^{1} \mathrm{em}$ ambas as línguas?

1. Embora se saiba que o conceito de "equivalência" não é confortável no campo dos Estudos da Tradução, pelo fato de pesquisas já terem mostrado que toda equivalência é relativa, utilizamos o termo aqui como mera forma de enfatizar a necessidade de relações semânticas entre as escolhas linguísticas dos poemas originais em comparação com as escolhas dos poemas traduzidos. Nesse sentido, concordamos com Baker (1992) sobre o uso do termo mais como conveniência do que como elemento polemizador. 
A Linguística Sistêmico-Funcional (doravante LSF) tem sido uma teoria muito usada em investigações no campo da linguística literária, inaugurada em Halliday (1973) e explorada em Hasan (1989), Montgomery (1993) e Simpson (1993), e suas aplicações às abordagens textuais da tradução (cf.: Munday 2001) que privilegiam o texto literário (por exemplo, Costa 1992; Vasconcellos 1997; Bueno 2005; Pagano 2008; Rodrigues-Júnior \& Barbara 2013; Rodrigues-Júnior no prelo). Em termos sociais, ao tentar explicar a estrutura e os fenômenos linguísticos levando em conta o papel que a língua desempenha em nossas vidas, a LSF se configura em uma abordagem valiosa por nos proporcionar uma melhor compreensão sobre a natureza e o uso da linguagem em geral; um exemplo disso está justamente no entendimento do texto literário como uma das formas de constituição de realidades de mundo (ficcional). Esse sistema, projetado para levar em conta a natureza dos padrões internos, semânticos e sintáticos da língua, é bastante sugestivo aos estudos literários, porque representa uma caracterização geral das funções semânticas do sistema linguístico peculiar a esse tipo de texto (cf.: Halliday 1973).

Em suporte à análise tradutória, Halliday (2001) também esclarece a relevância de se analisar a função do conteúdo ideacional na formação discursiva de realidades políticas, sociais e culturais relacionadas tanto à cultura de chegada quanto à de partida. Essa mesma ideia foi ratificada por Vasconcellos (1997), citada por Rodrigues-Júnior (2006b:58), quando esclarece ser necessária uma abordagem linguística tradutória que vá além do texto, "que se preocupe com a constituição de significados expressos no texto e sua relação com os contextos social, cultural e político mais amplos nos quais se insere o texto sob análise".

Para alcançar o objetivo proposto, pautamo-nos na metodologia de análise textual utilizada em pesquisas no campo das abordagens textuais da tradução: i) o mapeamento dos elementos ideacionais nos poemas originais e traduzidos; ii) a identificação das mudanças nas escolhas de processo, participante e circunstância e, portanto, nos significados ideacionais em relação aos originais; iii) a discussão de como se deu a representação ficcional de Álvaro de Campos na tradução, em comparação com o original, a partir das escolhas léxico-gramaticais de transitividade do tradutor, enfocando as possíveis mudanças de escolhas de processo, participante e circunstância. 
Para a análise proposta, o corpus foi delimitado pelos trinta e três (33) poemas ${ }^{2}$, do heterônimo pessoano Álvaro de Campos, traduzidos por Richard Zenith $(1998)^{3}$, cujos originais foram editados e organizados por Teresa Rita Lopes (2007). Faz-se necessário mencionar que o tradutor, Richard Zenith, tem recebido notório reconhecimento por seus trabalhos, tendo sido o vencedor do Morton Harold Landon Awards de 2006, pela Academy of American Poets ${ }^{4}$, prêmio que é concedido anualmente a tradutores norte-americanos que tenham publicado exímias traduções de poetas estrangeiros.

A obra de Campos foi dividida por Lopes (2010) em duas épocas: a primeira, que compreende os anos de 1913 e 1914, intitulada O Poeta Decadente, é a fase em que ele "se nutria de cultura francesa [...] e se exprimia num verso ainda obediente ao metro e à rima, embora com voluntárias e displicentes dissonâncias" (Lopes 2010:21). Dessa fase, que chamaremos Época I, há dois poemas traduzidos por Zenith. A segunda época, que chamaremos de Época II, foi dividida em quatro fases: a do Engenheiro Sensacionista, denominada aqui de Fase I, que é, a princípio, a fase das grandes odes e compreende o período entre 1914 e 1922, da qual há três poemas traduzidos. Em seguida, de 1923 a 1930, temos a fase do Engenheiro Metafísico, ou Fase II, que, segundo Lopes (2010:22), apresenta um Campos “já incapaz de se atordoar com o lá-fora da vida, às voltas na cama da sua insônia de ser”. Dos poemas traduzidos por Zenith (1998), a maioria encontra-se nessa fase, que são dezesseis ao todo. Na última fase, a do Engenheiro Aposentado, ou Fase III,que vai de1931 a 1935, vemos um Campos mais velho, mais cansado e desencantado (Lopes 2010), na qual temos 10 poemas. Finalmente, da fase que Lopes (2010) chama de Post Scriptum, Fase $I V$, temos dois poemas. Essa fase é composta pelos poemas que Pessoa escreveu depois da suposta morte de Campos, mas, por terem sido escritos com a mesma voz do heterônimo, são a ele atribuídos. A esse

2. O recorte desta pesquisa foi feito segundo o número de poemas que foram traduzidos por Richard Zenith (1998), dispersos em diferentes épocas da vida de Pessoa.

3. Os poemas em português são de domínio público e estão disponíveis em vários sítios eletrônicos; os poemas traduzidos foram copiados a partir da obra citada: Zenith (1998). Essa ação é resguardada, no âmbito acadêmico, pela Lei de Direitos Autorais, Artigo 46, Lei 9.610/1998, que trata das reproduções de obras autorais.

4. Esses prêmios constam tanto no sítio eletrônico de notícias da Universidade de Princeton, quanto em www.poets.org, ambos acessados em setembro de 2012. 
respeito, Lopes (2010:42) pondera: "Mas o fim real da vida de Pessoa só ocorrerá nove meses depois, durante os quais não pôde, afinal, passar sem Campos - essa máscara tão companheira da sua vera cara”.

As traduções ${ }^{5}$ analisadas fazem parte de uma obra maior, intitulada Fernando Pessoa \& Co., que teve, inicialmente, como público-alvo os Estados Unidos, país onde foi publicada pela primeira vez, aproximadamente 85 anos após a escrita original do primeiro poema. $\mathrm{O}$ corpus da pesquisa em si compreende, ao todo, 33 poemas; contudo, para os propósitos deste artigo, foram selecionados 10 excertos em que ocorreram mudanças (cf.: Catford 1965) significativas, que geraram escolhas tradutórias distintas, em nível de delicadeza (cf.: Halliday \& Matthiessen 2004:22), e de mudanças ideacionais. Os elementos oracionais investigados são descritos no próximo subitem.

\section{Elementos léxico-gramaticais analisados}

Visto que o foco desta pesquisa está na construção das representações linguísticas de Álvaro de Campos, interessa-nos apenas a metafunção ideacional, por meio da qual construímos linguisticamente nossas realidades de mundo. Como esclarecem Halliday \& Matthiessen (2004:29), "a língua materializa, em sua constituição, lances da experiência humana" , i.e., a primeira possibilita a formação da segunda. Por meio do componente experiencial, podemos analisar os recursos gramaticais envolvidos na interpretação das experiências de mundo do falante/escritor registrados em cada oração. Como a metafunção ideacional também reflete o valor contextual de campo (variável do Registro), ou seja, a natureza do processo social em que a língua está implicada, ela nos permite investigar as escolhas feitas no sistema de Transitividade, também denominada gramática da experiência. A transitividade nos permite analisar os tipos de processo, de participantes e de circunstâncias em cada oração. Os processos são realizados linguisticamente pelos grupos verbais das orações e os participantes pelos grupos nominais, sendo, então, aqueles que participam diretamente do processo. As circunstâncias realizam-se pelos grupos adverbiais ou

5. Para os poemas em português, veja Lopes (2010), e para as traduções, Zenith (1998). 6. Nossa tradução de: "language provides a theory of human experience". 
sintagmas preposicionados, que se referem ao lugar de um evento no tempo e espaço, seu modo, ou sua causa, e nos dão noções de 'quando, onde, como e por quê' algo acontece.

Um exemplo da aplicação do sistema de transitividade à análise de textos poéticos pode ser vista em Rodrigues-Júnior (2013), que discute a relação heteronímica entre Fernando Pessoa e Álvaro de Campos, com o intuito de problematizar a relação identitária entre ambos por meio das escolhas ideacionais no poema Tabacaria e sua tradução The Tobacco Shop. Ao selecionar as ocorrências das palavras "eu" e "mim", em português, e " $P$ ", "myself" e " $m e$ ", em inglês, RodriguesJúnior analisou as escolhas de transitividade que Campos fez para se auto-representar. O objetivo do estudo foi o de responder se Campos era realmente Pessoa, porém mais extrovertido, e como essa relação foi retextualizada na língua inglesa. As escolhas feitas pelo tradutor "desnudam a imagem melancólica e inerte em que Álvaro de Campos insistia em permanecer" (Rodrigues-Júnior 2013:222), pois, em todo o poema, Campos revela-se mais como paciente de ações, o que lhe atribui um "caráter de passividade" nas ações que empreendia. O pesquisador conclui que o heterônimo apresenta, em suas experiências de mundo incertas e desventuradas, não a extroversão esperada, mas a mesma tibieza e insegurança que acometiam o próprio Pessoa; no entanto, esclarece que essa "relação (auto)biográfica, ao contrário de ser direta e potencialmente explícita, é, de fato, sutil” (p.227), sendo necessárias investigações mais extensas, de caráter contrastivo e em momentos análogos, entre as escritas do heterônimo (Campos) e do ortônimo (Pessoa).

A partir das discussões feitas por Rodrigues-Júnior (2013), decidimos ampliar o escopo do corpus e da análise, associando à perspectiva sistêmico-funcional que orienta esta pesquisa o conceito de mudança de Catford (1965) com o intuito de analisar funcionalmente a língua, com foco no contexto.

Para que se entenda o conceito de mudança de Catford (1965), faz-se necessário mencionar a correspondência formal, que consiste na correspondência das categorias entre uma língua e outra, ou entre a língua-alvo e a língua-fonte (como classes gramaticais, por exemplo). Quando essa correspondência diverge, temos, então, uma mudança. As mudanças são divididas em dois tipos: (i) mudança de nível, que 
consiste em uma modificação de um termo gramatical para um termo lexical de uma língua para outra; e (ii) mudança de categoria, que se subdivide em quatro: 1. Mudança estrutural, em que a língua-fonte, ao ser traduzida, sofre uma modificação na estrutura gramatical da oração. 2. Mudança de classe, que é a mudança de classe gramatical da língua-fonte para a língua-alvo. 3. Mudança de unidade, que se refere às modificações ocorridas nas unidades linguísticas, tais como sentença, oração, grupo, palavra e morfema. 4. Mudança intra-sistema, que é quando a língua-fonte, apesar de possuir um sistema parecido com o da língua-alvo, terá seu sistema modificado na tradução, como, por exemplo, o uso de artigo definido em uma, indefinido em outra.

Em uma rediscussão do conceito de mudança de Catford, Matthiessen (2001) esclarece que mormente ocorrem, nas realizações linguísticas entre línguas, escolhas típicas da estrutura de cada língua, mas que apontam para mudanças metafuncionais singulares. $\mathrm{O}$ autor dá exemplos de mudanças entre metafuncões (e.g. no original, o eixo da oração constitui-se pelo construto semântico de processos materiais e na tradução este mesmo eixo foi retextualizado enfatizando-se os recursos linguísticos da metafunção interpessoal). A preocupação deste linguista é a construção semântica entre sistemas linguísticos, de base tipológica; no caso deste artigo, o interesse recai sobre a focalização da metafunção ideacional e suas mudanças de realização da língua portuguesa para a inglesa, sem ampla discussão de como os sistemas dessas línguas se comportam. É fato, contudo, que as proposições feitas por Matthiessen (2001) embasaram nossas análises, as quais sinalizam mudanças no âmbito da metafunção ideacional.

Com base nessa discussão, essa perspectiva será utilizada apenas para os excertos, no total de dez, que mostraram divergência nos tipos processuais, como mencionado anteriormente. No subitem seguinte, apresentamos os procedimentos de análise dos dados.

\section{Procedimentos metodológicos para a análise dos dados}

A categorização dos elementos oracionais adotada para a análise do corpus consistiu, primeiramente, na identificação dos processos, que é o que marca a experiência de mundo por meio do grupo verbal 
da oração, cujo participante principal fosse Álvaro de Campos. Após a identificação dos processos, procedeu-se à sua classificação, por meio da análise dos papéis semânticos desempenhados por Campos (Ator, Experienciador, Portador, Comportante, Dizente ou Existente). As orações selecionadas foram as de primeira pessoa do singular, ou seja, o "eu (I)" e "o mim (me)", que representam linguisticamente o participante, nesse caso, o próprio Campos, envolvido nas ações, comportamentos, percepções, gostos, atributos e falas desse heterônimo. Em seguida, cada oração classificada foi posta em paralelo com sua respectiva oração no original. Vale ressaltar que ambas as classificações (original e tradução) foram feitas separadamente, a fim de que não houvesse influência da análise de uma língua para a outra.

Uma vez concluída a classificação dos processos, outro recorte foi feito: o foco para uma análise tradutória mais aprofundada passou a ser aqueles processos que apresentavam diferenças entre suas categorias gramaticais (e possivelmente semânticas), considerando-se também o conceito de mudança de Catford (1965). No escopo deste artigo, este conceito se expande de "mudança-classe gramatical" para o de "mudança ideacional", i.e. mudanças nos níveis da ideação (processos, participantes, circunstâncias e expansões). Esse recorte, com foco nas divergências do sistema de transitividade e na mudança proposta por Catford (1965), resultou em dez excertos, que mostraram claramente as mudanças ideacionais sugeridas e que sintetizam o total dessas mudanças.

\section{Análises}

Após termos analisado o sistema de transitividade de todos os versos dos poemas que compõem o corpus desta pesquisa, selecionamos os versos em que o "eu" lírico figura como participante do evento oracional e cujo processo apresentou discrepância em termos de categorização.

\section{Excerto 1}

No primeiro poema, Quando olho para mim não me percebo / I study myself but I can 't perceive, há apenas uma divergência em termos de escolha de processo, como podemos observar no verso 7 abaixo: o 
Processo Mental (3b), ao ser traduzido, permanece como Mental, mas com um construto semântico distinto do processo do original:

\begin{tabular}{c|c|c|c|c|c}
$7^{*} . \mathrm{E}$ & $\mathrm{eu}$ & & nunca & sei & como hei de concluir \\
\hline--- & $I$ & 've & never & discovered & how to resist \\
\hline & $(1)$ & $(3 \mathrm{a})$ & $(2)$ & $(3 \mathrm{~b})$ & $(4)$
\end{tabular}

No poema original, doravante PO, o participante (1) é o Experienciador, e o Processo Mental (3b) apresenta, como metafenômeno (cf.: Halliday \& Matthiessen 2004:204), o conteúdo experiencial do mundo interior desse participante, ou seja, a oração (4) realiza linguisticamente o mundo da consciência do "eu". Essa ideia, que continua no próximo verso, revela ao leitor parte do mundo cognitivo do "eu" lírico: E eu nunca sei como hei de concluir / As sensações que a meu pesar concebo.

No poema traduzido, doravante PT, o participante é também denominado "Experienciador", e o Processo que foi classificado como Mental, (3b), apresenta um caráter diferente do Processo Mental do PO, pois seu papel semântico é o de expressar uma ação subjetiva, interna. No entanto, dentre os significados de "discover", presentes no Oxford Advanced Learner's Dictionary (Hornby 2007), temos o seguinte: "Ser a primeira pessoa a se tornar consciente que um lugar ou coisa particular existe" e "encontrar informações sobre algo" Nesse caso, o Processo Mental não condiz com "fazer" algo concretamente, como poderia se conceber à primeira vista, mas se inscreve no mundo subjetivo do "eu" lírico, porque sua realização linguística se insere no campo semântico da ação subjetiva. Nesse caso, houve uma mudança ideacional em nível semântico, pelo caráter de escolhas léxico-gramaticais das línguas em jogo.

A consideração que pode ser feita nesse sentido é que o tradutor imputou a "discovered" os significados acima citados, i.e. a ideia de "perscrutar" e "desvendar", impingindo a esse processo o peso

*. A numeração dos versos corresponde aos poemas, no total de 33, que foram analisados, dos quais apenas 10, que sintetizam os resultados alcançados, são apresentados neste artigo. 
semântico de um Processo Mental do tipo Cognitivo (cf.:Halliday \& Matthiessen 2004:210); e a mudança estrutural (cf.: Catford 1965) que acontece no processo se dá exatamente para aproximar semanticamente os dois tipos de processos.

\section{Excerto 2}

No poema Tabacaria / The Tobbaco Shop, no verso 26, cujas duas orações serão apresentadas separadamente, ocorre uma permuta de processos: a primeira oração, no PO, é constituída por um Processo Material (4), e a segunda, por um Processo Relacional (8); no PT, essa classificação se inverte.

26. Como
\begin{tabular}{c|c|c|c|c} 
Since & $I$ & não & fiz & propósito nenhum, \\
\hline$(1)$ & $(2)$ & $(3)$ & had & no ambition, \\
\hline \multicolumn{2}{c|}{ talvez } & tudo & fosse & nada. \\
\hline perhaps & $I$ & failed & in nothing. \\
\hline$(6)$ & $(7)$ & (8) & $(9)$
\end{tabular}

Na primeira oração, o participante (2), implícito no PO, configurase como Ator. No entanto, esse Ator nos fala de uma ação que deixou de fazer no seu mundo material, ou seja, deixou de alcançar a sua Meta (5). No PT, o participante (2) torna-se Portador, cujo Atributo (5) se configura como uma qualidade (posse) inexistente. Na segunda oração, o participante (7) do PO configura-se como Portador de um Atributo (9) que reflete o conteúdo semântico que lhe é oposto (tudo vs. nada). No PT, como o Processo é Material, o "eu" lírico se torna Ator, a cuja oração que representa a realidade de mundo ficcional de Campos adiciona-se a circunstância in nothing, que, segundo Halliday \& Matthiessen (2004:280), expressa um aspecto semântico de abstração ${ }^{8}$. Devido a essas alterações, perde-se, à primeira vista, o contraponto semântico entre "tudo" e "nada" na tradução.

8. Segundo Halliday \& Matthiessen (2004:280), a interpretação de circunstâncias desse tipo deve levar em conta os aspectos sistêmicos da língua, sobretudo o registro. Por se tratar de arte verbal (literatura), em que o eu lírico é uma representação ficcional, o texto poético se presta a realizações léxico-gramaticais dessa ordem de abstração. 


\section{Excerto 3}

No verso 115, o evento é o Processo Material tirar (4), localizado na oração projetada,estabelecido semioticamente pelo Processo Mental quis (3), sugerindo que se tratava de um desejo cuja ação não foi realizada. Na tradução, o evento se constitui de dois Processos Materiais, went e to take off, ambos em (3), indicando, em língua inglesa, uma ação prestes a acontecer:

\begin{tabular}{c|c|c|c} 
115. Quando & & quis & tirar a máscara, \\
\hline When & $I$ & went & to take off the mask, \\
\hline$(1)$ & $(2)$ & $(3)$ & $(4)$
\end{tabular}

No PO, o "eu" lírico, implícito em (2), é construído como Ator pelo grupo verbal (3) e o termo (4) é caracterizado como projeção, ocorrendo o mesmo na tradução. Contudo, no PO, Campos relata um sentimento: o de "querer" fazer algo, e Campos no PT parece ser mais agente, pois tentou tirar a máscara, e não somente 'quis' tirá-la. Temos, assim, uma mudança ideacional.

\section{Excerto 4}

No Poema Adiamento / Referral, no verso 14, no PO, o Processo Relacional (2a) se transforma, no PT, em um Processo Mental representado abaixo por (2a), (2b) e (2c):

\begin{tabular}{c|c|c|c|c|c|c}
14. & Tenho & já & & o plano traçado & & {$[\ldots]$} \\
\hline$I$ & 've & already & planned & it & out & {$[\ldots]$} \\
\hline$(1)$ & $(2 \mathrm{a})$ & $(3)$ & $(2 \mathrm{~b})$ & $(4)$ & $(2 \mathrm{c})$ &
\end{tabular}

No PO, o Processo Relacional (2a) coloca o "eu” lírico em posição de Portador (1) do Atributo (4), traçando uma relação de possessão entre os participantes desse evento. No PT, o Processo Mental representado por (2a), (2b) e (2c) faz do "eu" lírico um Experienciador (1) e adiciona ao evento o Fenômeno (4). Podemos apontar também uma mudança de nivel (cf.: Catford 1965), em que o Fenômeno it (4) não representa o composto com verbo na forma do present perfect. 
No nível da oração, pode-se dizer que a construção semântica permanece, mas, na metafunção ideacional, um perfil diferente está sendo construído para o "eu" lírico; temos novamente um Campos Ator, ou seja, mais agente que paciente e, portanto, temos mais uma mudança ideacional.

\section{Excerto 5}

No Poema Aniversário / Birthday, verso 6, o Processo Relacional (2) se transforma em Mental no PT:

\begin{tabular}{c|c|c} 
6. Eu & tinha & a grande saúde de não perceber coisa nenhuma, \\
\hline$I$ & enjoyed & the good health of understanding nothing, \\
\hline$(1)$ & $(2)$ & (3)
\end{tabular}

Essa modificação faz com que o "eu" lírico que, no PO, é Portador (1), transforme-se em Experienciador, e o Atributo (3) torne-se um Fenômeno. Dentro desse Fenômeno, apesar de os vocábulos "perceber" e "understanding" pertencerem à mesma classe (ao mesmo sistema), eles não se correspondem completamente em termos semânticos, formando, assim, uma mudança intra-sistema. "Understand" poderia apenas ser sinônimo de "perceber", conforme o Oxford Advanced Learner's Dictionary (Hornby 2007), somente se o sentido fosse "entender ou pensar em alguém/algo de uma forma particular" . Como este não é o caso, não temos equivalência semântica total. Pelo contexto do poema, parece-nos que "perceber" conota "reparar", "notar", e não "compreender", pois no verso 10 ("Quando vim a olhar para a vida, perdera o sentido da vida"), Campos nos diz que começou a perceber a vida somente mais tarde, quando já não tinha mais sentido. A partir disso, temos, então, uma mudança ideacional, manifestada, sobretudo, pela distinção dos elementos semânticos que apontam para a variável de campo do registro.

9. Nossa tradução de: "to understand or think of somebody/something in a particular way". 


\section{Excerto 6}

Ainda desse mesmo poema, no verso 11, o Processo Relacional (4) se torna Mental:

\begin{tabular}{c|c|c|c|c} 
11. Sim, & o que & & fui & de suposto a mim-mesmo, \\
\hline Yes, & the person & $I$ & knew & as me, \\
\hline$(1)$ & $(2)$ & $(3)$ & $(4)$ & $(5)$
\end{tabular}

Com essa alteração, o "eu" lírico deixa a esfera do "ser" e vai para a da "cognição", assim temos a seguinte classificação: no PO, o Portador é o "eu" implícito indicado por (3), o Atributo é o termo (2), e a Circunstância de Elaboração/Papel é indicada por (5). No PT, o Experienciador é o termo indicado por (3), o Fenômeno é o (2), e o tipo de circunstância permanece inalterado. Nesse excerto, mantém-se uma mudança ideacional no nível semântico do processo, que modifica parcialmente a experiência de mundo ficcional de Álvaro de Campos, situando-o, no original, como Portador, e na tradução, como Experienciador.

\section{Excerto 7}

No poema 19, Não! Só quero a liberdade / No! All I want is freedom, o Processo Mental (3) do verso 7 é transformado em Relacional.

\begin{tabular}{l|c|c|c|c}
7. & & Não sinto & & em sociedade por quotas, \\
\hline And & $I$ & ' $m$ & unable to feel & in jointly held society. \\
\hline$(1)$ & $(2)$ & $(3)$ & $(4)$ & (5)
\end{tabular}

No PO, o "eu" lírico é o Comportante do processo, implícito em (2), por não haver a realização linguística daquilo que é sentido ou percebido: trata-se exatamente da ausência de emoção, de sentimento ("Não sinto"), e esta experiência é delimitada pela Circunstância de Localização (5), ou seja, o "eu" lírico sente apenas em sociedade por quotas. O Comportante se torna Portador (2) no PT, cujo Atributo (4) tem o papel de representar a inabilidade/impossibilidade de "sentir", também restringida pelo mesmo tipo de circunstância.

Uma mudança de nível ocorre neste verso, porquanto o processo 
quer dizer: ser/estar inapto a sentir. Essa retextualização altera também a construção do "eu" lírico, pois ele deixa de ser alguém que não sente no PO, e se torna alguém que não consegue sentir no PT. Essa mudança é, portanto, ideacional.

\section{Excerto 8}

No poema 20, "Ora até que enfim..., perfeitamente" / "At long last... no doubt about it”, dois versos apresentaram processos distintos.

No verso 3, o Processo Relacional (4) se torna Material:

\begin{tabular}{c|c|c|c|c|c|c} 
& & & Tenho & a loucura & exatamente & na cabeça. \\
\hline Madness & has & definitely & entered & my head. & & \\
\hline$(1)$ & $(2)$ & $(3)$ & $(4)$ & $(5)$ & $(6)$ & (7)
\end{tabular}

No PO, o "eu" lírico implícito se caracteriza como Portador do Processo Relacional (4), o termo (5) como Atributo possessivo e o termo (7) como Circunstância de Localização. No PT, o termo (1) é Ator, e (5) é Meta do Processo Material (4).

Esse excerto apresenta também uma mudança estrutural (cf.: Catford 1965) em termos oracionais. Há uma alteração lexical ("ter" se torna "enter"); e há também uma mudança ideacional, pois, no PO, o "eu" lírico se configura como proprietário da loucura, o que leva a subentender que ele tenha controle sobre a loucura que está em sua cabeça. No PT, a cabeça do "eu" lírico é paciente da ação perpetrada pela loucura (a de entrar em sua cabeça), modificando, assim, a relação entre "eu" lírico e a loucura, que é o tema principal do poema.

\section{Excerto 9}

Ainda no poema Ora até que enfim..., perfeitamente / At long last... no doubt about it, no verso 5, o Processo Relacional (3) se torna Material no PT:

\begin{tabular}{c|c|c|c|c} 
5. E & a minha cabeça & teve & o sobressalto & pela espinha acima... \\
\hline And & the shock & went up & my spine & to my head... \\
\hline$(1)$ & $(2)$ & $(3)$ & $(4)$ & (5)
\end{tabular}


No PO, temos a seguinte classificação: (2) caracteriza-se como Portador e (4) como Atributo (coisa possuída) do Processo Relacional. O termo (5) é a Circunstância de Meio. No PT, (2) caracteriza-se como Ator, (4) como Escopo do Processo Material e (5) como Circunstância de Localização.

Assim, o Portador que, no PO, representa uma parte do corpo do "eu" lírico ("a minha cabeça"), torna-se "the shock", passando a ser o Ator do processo. O mesmo acontece com o Atributo "sobressalto", que passa a ser "my spine", funcionando como Escopo do Processo Material, e com as circunstâncias que modificam a experiência do "sobressalto" em cada uma das textualizações. Essas mudanças, embora também sejam devidas à estrutura linguística de cada língua, (re) textualizam o "eu" lírico de formas distintas, o que nos leva a perceber mudanças ideacionais nesse trecho.

\section{Excerto 10}

No poema Dobrada à moda do Porto / Oporto-Style Tripe, no verso 9, o Processo Material (3) se torna Mental no PT:

\begin{tabular}{c|c|c|c|c} 
9. $\quad$ E & & vim & passear & para toda a rua. \\
\hline And & $I$ & decided & to take a walk & down the street. \\
\hline$(1)$ & $(2)$ & $(3)$ & $(4)$ & $(5)$
\end{tabular}

No PO, o "eu" lírico elidido é Ator (2) do processo e (5) é a Circunstância de Benefício. No PT, o "eu" lírico será Experienciador hibridizado de Ator pela ação de "to take a walk", (3) e (4), e (5) será uma Circunstância de Localização.

Além da evidente mudança estrutural, as alterações no sistema de transitividade apontam para uma mudança ideacional. No PT, o "eu" lírico tomou a decisão de passear, mas no PO é como se ele já estivesse passeando. Ademais, a circunstância no PT nos mostra onde Campos decide passear ("down the street"), mas no PO ele nos diz para quem veio passear ("para toda a rua"). 


\section{Discussões e considerações finais}

Ao aliar o conceito de mudança de Catford (1965) à análise do sistema de transitividade proposto por Halliday \& Matthiessen (2004), sugerimos o termo mudança ideacional para classificar aquelas alterações que contribuíssem para uma construção semântica diferente do original. Ou seja, as mudanças ideacionais contribuíram para uma interpretação diferente de Álvaro de Campos. No excerto 1, na tradução, perdeu-se o jogo de máscaras que o "eu" lírico cria, sendo também possível interpretá-lo como alguém que precisa lutar contra (ou resistir a) suas próprias emoções, enquanto que, na língua-fonte, temos um Campos mais consciente de si, mais racional diante de suas emoções, mais parecido talvez com o próprio Pessoa: o idealizador de todas as máscaras que figuram em sua poesia.

Os excertos 2, 3, 4 e 5 apresentaram mudanças ideacionais, com certas distinções no construto semântico do PT em relação ao PO, visto que, na tradução, interpretamos um Campos mais dinâmico, mais agente que paciente. O excerto 6 também contribui para uma construção ideacional diferente do original; como demonstrado nas análises, um dos termos não apresentou equivalência semântica aceitável. Tanto no primeiro quanto no segundo excerto, o "eu" lírico pôde ser concebido como alguém mais emocional, em virtude da alteração dos tipos de processo (Relacional para Mental) que ocorreu em ambos.

Considerando a mudança de nível que ocorre no excerto 7, juntamente com a modificação de seu processo, a mudança ideacional foi bastante sutil, pois a esfera a que pertence o "eu" lírico no verso original é a do "sentir", enquanto que a da tradução é a do "ser". Em outras palavras, o leitor do PT pode inferir um Campos incapaz de sentimento, quando, na verdade, o que ele nos diz pode ser simplesmente uma escolha sua e não necessariamente uma incapacidade.

Nos excertos 8 e 9 , constatamos uma mudança ideacional na construção do "eu" lírico, referente à sua relação com o tema principal do poema, enquanto o excerto 10 apresentou mudanças apenas no sistema de transitividade.

Por meio das modificações que ocorreram no estrato da léxicogramática, foi possível observar, nos excertos analisados, que o mundo 
experiencial construído comparativamente pelo "eu" lírico no texto de partida e no texto de chegada foi, na maioria das vezes, alterado, embora também possamos concluir que, em virtude das especificidades léxico-gramaticais de cada língua, português e inglês, o tradutor conseguiu, até certo ponto, manter o texto dentro de uma esfera semântica equivalente à do original. Portanto, a variação dos tipos de processos ou a ocorrência das mudanças, nesse caso, mudanças ideacionais, nem sempre significa mudança na equivalência semântica.

Podemos concluir que, segundo Arrojo (1986) e Laranjeira (2003), é possível desconstruir os preconceitos da tradução de poesia; ou seja, "não só o poema pode ser traduzido, [como] pode instaurar um 'texto' na língua-cultura de chegada tão válido quanto qualquer outro texto produzido nessa mesma língua-cultura" (Laranjeira 2003:146). No entanto, para que isso aconteça, a tradução de poemas, considerando-se a singularidade intrínseca que possui, só pode ser bem executada por profissionais que dominem não somente os dois idiomas e culturas, mas que estejam profundamente envolvidos com o autor, sua história e sua inteira obra literária, como é o caso de Richard Zenith, que não é somente tradutor de Pessoa, mas, sobretudo, pesquisador e estudioso de sua vida e obra.

Todavia, em relação às mudanças ideacionais que apontamos, devemos lembrar que um texto não possui apenas uma leitura, tampouco uma interpretação única (cf.: Laranjeira 2003), especialmente o texto poético, que se posiciona em uma esfera semântica superior para expressar os sentidos que no poema se constroem. Essas alterações, se assim podemos considerá-las, são a voz do tradutor-escritor por trás da voz de Álvaro de Campos, pois, como aponta Laranjeira (2003), o tradutor não se apaga; de fato, ele reproduz o estilo do autor, mas deixa transparecer seu próprio estilo, que consiste em sua interpretação do poema, sua compreensão e versão do mundo de Campos para o seu próprio mundo. 


\section{Referências Bibliográficas}

Arrojo, R. 1986. Oficina de Tradução: a teoria na prática. São Paulo: Editora Ática.

BAKER, M. 1992. .In Other Words: a course book on translation. Londres; Nova York: Routledge.

BASSNETT, S. 2003. Estudos de tradução: fundamentos de uma disciplina. Lisboa: Fundação Calouste Gulbenkian.

Воотн, W. 1980. A Retórica da Ficção. Lisboa: Arcádia.

Bueno, L. 2005. Transitividade, Coesão e Criatividade Lexical no Corpus Paralelo Macunaíma, de Andrade e Macunaíma, de Goodland. 176 fl. Dissertação (Mestrado em Estudos Linguísticos) - Fale, UFMG: Belo Horizonte.

Buescu, H. C. 2010. Alteridade/Impessoalidade. In: Martins, Fernando Cabral (coord.). Dicionário de Fernando Pessoa e do Modernismo Português. São Paulo: Leya. p. 40-42.

CAtrord, J. C. 1965. A Linguistic Theory of Translation. Oxford: Oxford University Press.

CostA, W. C. 1992. A Linguistic Approach to the analysis and evaluation of translated texts with special reference to selected texts by J. L. Borges. 350fl. Tese (Doutorado em Linguística) - University of Birmingham: Birmingham, Inglaterra.

Halliday, M. A. K. 1973. Exploration in the Functions of Language. Londres: Edward Arnold.

Halliday, M. A. K. 2001. Towards a Theory of Good Translation. In: Steiner, E.; YAllop, C. (org.) Exploring Translation and Multilingual Text Production: beyond content. Berlin; Nova York: Mouton de Gruyter. p.229-245.

Halliday, M. A. K.; Mathiessen, C. M. I. M. 2004. An Introduction to Functional Grammar. 3ed. Londres; Nova York: Arnold.

Hasan, R. 1989. Linguistics, Language and Verbal Art. Oxford: Oxford University Press.

HornBy, A.S. 2007. Oxford Advanced Learner's Dictionary. $7^{\mathrm{a}}$ ed. Oxford: Oxford University Press.

Laranjeira, M. 2003. Poética da tradução: do Sentido à Significância. São Paulo: Editora da Universidade de São Paulo.

Lopes, T. R. (org.). 2007. Fernando Pessoa: Poesia Completa de Álvaro de Campos. São Paulo: Companhia das Letras.

. CAmpos, Álvaro de. 2010. In: Martins, Fernando Cabral (coord.). Dicionário de Fernando Pessoa e do Modernismo Português. São Paulo: Leya. p. 123-131. 
Martins, F. C. (coord.). 2010. Dicionário de Fernando Pessoa e do Modernismo Português. São Paulo: Leya.

Matthiessen, C. M. I. M. 2001. The Environments of Translation. In: Steiner, E.; Yallop, C. (org.) Exploring Translation and Multilingual Text Production: beyond content. Berlin; Nova York: Mouton de Gruyter. p. 41-124.

Montgomery, M. 1993. Language, Character and Action: A Linguistic Approach to the Analysis of Character in a Hemingway Short Story. In: SincLaIR, J. M. et alii (org.) Techniques of Description. Londres; Nova York: Routledge. p. 127-142.

Munday, J. 2001. Introducing Translation Studies: theories and applications. Londres; Nova York: Routledge.

Pagano, A. 2008. Abordagens Sistêmicas da Tradução. In: CoulthardCaldas C. R., Scliar-Cabral, L. (org.). Desvendando Discursos. Florianópolis: Editora da UFSC. p. 255-288.

Rodrigues-JÚNIOR, A. S. 2006. Abordagens Discursivas dos Estudos da Tradução. Porto: Revista Polissema, Instituto Superior de Contabilidade e Administração do Porto, v. 6, p. 41-64.

Rodrigues-JÚnior, A. S. 2013. Representações do mundo (íntimo) de Fernando Pessoa e Álvaro de Campos em Tabacaria e em sua tradução The Tobacco Shop. In: Vian JR., O.; Caltabiano, C. (org.). Língua(gem) e suas múltiplas faces: estudos em homenagem a Leila Barbara. Campinas, SP: Mercado de Letras. p. 213-229.

RODRIGUES-JÚNIOR, A. S.. Tradução e Literatura Gay: formas de se fazer pesquisa no campo dos estudos da linguagem. São Paulo: Mercado de Letras, no prelo.

Rodrigues-JÚNIOR, A. S.; BARBARA, L. 2013. Linguistic Constructions of Appraisal in the Novel The Picture of Dorian Gray and its Brazilian Translation and Adaptations: an exploratory analysis. Revista Brasileira de Linguística Aplicada, v. 13, n. 1. p.229-255.

Simpson, Paul. 2004. .Language, Ideology and Point of View. Londres; Nova York: Routledge. 2004. Stylistics. Londres; Nova York: Routledge.

Vasconcellos, M. L. B. 1997. Retextualizing Dubliners: A SystemicFunctional Approach to Translation Quality Assessment. Tese (Doutorado em Inglês). Universidade Federal de Santa Catarina: Santa Catarina, Florianópolis.

Zentth, Richard. 1998. Fernando Pessoa \& Co: Selected Poems. Nova York: Grove Press. 